LETTER TO JMG

\title{
The potential for increased clinical sensitivity in genetic testing for polyposis colorectal cancer through the analysis of $\mathrm{MYH}$ mutations in North American patients
}

\author{
K Eliason, B C Hendrickson, T Judkins, M Norton, B Leclair, E Lyon, B Ward, W Noll, T Scholl
}

J Med Genet 2005;42:95-96. doi: 10.1136/jmg.2004.025973

M utations in the base excision repair gene $M Y H$ were recently implicated in recessive inheritance of colorectal adenomas and carcinomas. ${ }^{1}$ The majority of patient specimens screened for $M Y H$ and described in published reports derive from the United Kingdom, where two missense variants-Y165C and G382D-are the most prevalent mutations in the white population. ${ }^{2-5}$ The carrier frequency for these two mutations is approximately $2 \%$ in the British population. ${ }^{14}$ Some additional mutations were detected at lower frequency in these patients. Two other protein truncating mutations-E466X and Y90X-have been found in individuals of Indian and Pakistani descent, respectively. ${ }^{2}$ Finally, a mutation that deletes codon Glu466 was reported to be prevalent in Italian patients. ${ }^{6}$ This evidence supports the view that additional mutations will be discovered showing differences in prevalence between ancestries.

We determined the mutation spectrum for $M Y H$ by direct DNA sequencing in 219 anonymous North American patient specimens found negative for APC mutations during clinical genetic testing for risk assessment for familial adenomatous polyposis (FAP). All specimens were first sequenced for exons 7 and 13, where 13 instances $(5.9 \%)$ of biallelic mutations and 15 instances $(6.8 \%)$ of heterozygous mutations of either Y165C or G382D were detected (table 1).

The remaining 202 specimens with one or no mutations and with sufficient DNA were sequenced at $M Y H$ for all exons and intron-exon boundaries. Sequencing identified a second mutation in nine of the 15 heterozygous carriers of Y165C and G382D. Two of these mutations $-891+3 \mathrm{~A}>\mathrm{C}$ and 1103 delC-have been described previously, ${ }^{3}{ }^{4}$ while others (E182X, Q300X and IVS13+25del30) are novel. IVS13+25del30 was considered a mutation because it deletes 30 bases from an 85 base intron and therefore seems likely to interfere with RNA splicing. Also, one homozygous patient each for two previously reported mutations-E466X and 1395delGGA - were detected. Small deletions affecting exons within the MYH locus were excluded as potential causes for an apparent homozygous result in these patients by long range polymerase chain reaction extending from exons 1 to 16. A North American population frequency of $2 \%$ was determined by identifying three Y165C and seven G382D heterozygous carriers when 497 anonymous samples that were negative for clinical factor $\mathrm{V}$ Leiden tests were screened at exons 7 and 13. This carrier frequency is similar to that reported in two European studies. ${ }^{14}$

MYH mutations were also assessed in 306 anonymous North American specimens found negative for clinical testing in $h M L H 1$ and $h M S H 2$ as part of an analysis of risk for hereditary non-polyposis colorectal cancer (HNPCC). All 306 specimens were initially screened for Y165C and G382D; three specimens (1.0\%) carried biallelic mutations and 10 specimens $(3.3 \%)$ were heterozygotes. One instance of the

\section{Key points}

- MYH testing represents an important component of comprehensive genetic testing for polyposis colorectal cancer.

- If an initial screen for highly prevalent MYH mutations is used, then whole gene analysis of heterozygous carriers is necessary to identify other low prevalence mutations in order to obtain the maximum clinical sensitivity.

- Additional mutations in MYH will probably be discovered; screening methods should be capable of detecting novel mutations as they come to light.

$891+3 \mathrm{~A} \rightarrow \mathrm{C}$ mutation was found when the entire $M Y H$ gene was sequenced in these 10 heterozygous specimens. When an additional 50 of the HNPCC negative specimens were fully sequenced for $M Y H$, one heterozygous carrier for $1103 \mathrm{delC}$ was detected.

These results confirm other reports associating $M Y H$ mutations with colon cancer. In this set of 219 patients undergoing polyposis colon cancer genetic testing, 24 (11.0\%) carried biallelic MYH mutations. This percentage could increase if clinically uncertain missense variants detected in these patients are shown to cause disease (data not shown). Within these 24 patients, three reported having 6 to 19 polyps, nine had 20 to 99 polyps, three had 100 or more, and for nine the polyp status was unknown. APC testing alone identified deleterious mutations in $34.4 \%$ of all patients referred for FAP testing. When $M Y H$ testing was included, the positive rate increased to $41.3 \%$. It is reasonable to conclude that $M Y H$ testing represents an important component of comprehensive genetic testing for polyposis colorectal cancer.

These data support the conclusion that whole gene screening is required to attain the highest clinical sensitivity, as 11 of the 21 biallelic patients carried mutations other than Y165C and G382D. A role for MYH in non-polyposis patients is intriguing. These results show that a low percentage of patients diagnosed with HNPCC and undergoing testing for mutations in mismatch repair genes are biallelic or heterozygous MYH mutation carriers. However, as polyp data were not available for these samples, further studies are required for a better understanding of the role of $M Y H$ mutations in patients diagnosed with HNPCC.

Abbreviations: FAP, familial adenomatous polyposis; HNPCC, hereditary non-polyposis colorectal cancer 


\begin{tabular}{|c|c|c|c|}
\hline \multicolumn{2}{|l|}{ Genotype } & \multirow{2}{*}{$\begin{array}{l}\text { FAP negative samples } \\
(n=219)^{*}\end{array}$} & \multirow{2}{*}{$\begin{array}{l}\text { HNPCC negative samples } \\
(n=306)^{* *}\end{array}$} \\
\hline First mutation & Second mutation & & \\
\hline Y165C & Y165C & 4 & 1 \\
\hline G382D & G382D & 2 & $\ldots$ \\
\hline Y165C & G382D & 7 & 2 \\
\hline Y165C & $891+3 \mathrm{~A} \rightarrow \mathrm{C}$ & 1 & $\ldots$ \\
\hline Y165C & 1103 delC & 1 & $\begin{array}{l}\cdots \\
\cdots\end{array}$ \\
\hline Y165C & IVS13+25del30 & 1 & $\begin{array}{l}\cdots \\
\ldots\end{array}$ \\
\hline Y165C & Q300X & 1 & $\cdots$ \\
\hline Y165C & 1395delGGA & 1 & $\cdots$ \\
\hline G382D & 1395delGGA & 1 & $\ldots$ \\
\hline G382D & $891+3 \mathrm{~A} \rightarrow \mathrm{C}$ & 1 & 1 \\
\hline G382D & E182X & 1 & $\ldots$ \\
\hline G382D & 1103 delC & 1 & $\ldots$ \\
\hline E466X & E466X & 1 & $\ldots$ \\
\hline 1395delGGA & 1395delGGA & 1 & $\begin{array}{l}\cdots \\
\ldots\end{array}$ \\
\hline Y165C & - & 4 & 3 \\
\hline G382D & - & 2 & 6 \\
\hline 1103 delC & - & 1 & 1 \\
\hline IVS12-2 $A \rightarrow G$ & - & 1 & $\ldots$ \\
\hline \multicolumn{4}{|c|}{$\begin{array}{l}\text { All specimens were negative for whole gene clinical sequencing of } A P C \text { for FAP specimens and } h M L H 1 \text { and } h M S H 2 \\
\text { for HNPCC specimens. Mutations in bold were detected by whole gene sequencing of } M Y H \text {. A dash (-) } \\
\text { accompanies heterozygous carriers in the "second mutation" column. } \\
\text { *All heterozygotes after testing for } Y 165 C \text { and G382D and } 187 \text { samples without mutations received full sequence } \\
\text { testing. } \\
\text { **All heterozygotes after testing for } Y 165 C \text { and G382D and } 50 \text { randomly selected samples without mutations } \\
\text { received full sequence testing. }\end{array}$} \\
\hline
\end{tabular}

\section{Authors' affiliations}

K Eliason, B C Hendrickson, T Judkins, M Norton, B Leclair, B Ward, W Noll, T Scholl, Myriad Genetic Laboratories Inc, Salt Lake City, Utah, USA

E Lyon, Department of Pathology, University of Utah, Salt Lake City

Conflicts of interest: $K E, B H, T J, M N, B L, B W$, and TS are employed by $M G L$ Inc, the funding source for this research. EL declares no competing interests.

Correspondence to: Dr Thomas Scholl, Myriad Genetic Laboratories Inc, 320 Wakara Way, Salt Lake City, UT 84108, USA: tscholl@myriad.com

\section{REFERENCES}

1 Al-Tassan N, Chmiel NH, Maynard J, Fleming N, Livingston AL, Williams GT, Hodges AK, Davies DR, David SS, Sampson JR, Cheadle JP. Inherited variants of $M Y H$ associated with somatic $\mathrm{G}: \mathrm{C} \rightarrow \mathrm{T}: \mathrm{A}$ mutations in colorectal tumors. Nat Genet 2002;30:227-32.
2 Jones S, Emmerson P, Maynard J, Best JM Jordan S, Williams GT, Sampson JR, Cheadle JP. Biallelic germline mutations in MYH predispose to multiple colorectal adenoma and somatic $\mathrm{G}: \mathrm{C} \rightarrow \mathrm{T}: \mathrm{A}$ mutations. Hum Mol Genet 2002;11:2961-7.

3 Sampson JR, Dolwani S, Jones S, Eccles D, Ellis A, Evans DG, Frayling I, Jordan S, Maher ER, Mak T, Maynard J, Pigatto F, Shaw J, Cheadle JP. Autosomal recessive colorectal adenomatous polyposis due to inherited mutations of MYH. Lancet 2003;362:39-41.

4 Sieber OM, Lipton L, Crabtree M, Heinimann K, Fidalgo P, Phillips RK, Bisgaard ML, Orntoff TF, Aaltonen LA, Hodgson SV, Thomas HJ, Tomlinson IP. Multiple colorectal adenomas, classic adenomatous polyposis and germ-line mutations in MYH. N Engl J Med 2003;348:791-9.

5 Fleischmann C, Peto J, Cheadle J, Shah B, Sampson J, Houlston RS. Comprehensive analysis of the contribution of germline $\mathrm{MYH}$ variation to early-onset colorectal cancer. Int J Cancer 2004;109:554-8.

6 Gismondi V, Meta M, Bonelli L, Radice P, Sala P, Bertario L, Viel A, Fornasarig M, Arrigoni A, Gentile M, Ponz de Leon M, Anselmi L, Mareni C, Bruzzi P, Varesco L. Prevalence of the Y165C, G382D and 1395delGGA germline mutations of the MYH gene in Italian patients with adenomatous polyposis coli and colorectal adenomas. Int J Cancer 2004; 109:680-4. 